\title{
Religious Orientation and Its Relationship to Suicidality: A Study in One of the Least Religious Countries
}

\author{
Bob Lew ${ }^{1,+}{ }^{\text {, Jenny Huen }}{ }^{2,+}$, Lu Yuan ${ }^{3}$ (D), Steven Stack ${ }^{4}$, Thambu Maniam ${ }^{5}$, Paul Yip ${ }^{2,6}$, \\ Jie Zhang ${ }^{7,8}$ (D) and Cun-xian Jia ${ }^{3,7, *}$ \\ 1 Department of Social Psychology, Faculty of Human Ecology, Putra University of Malaysia, Serdang 43400, \\ Malaysia; boblew@asiacrux.com \\ 2 Department of Social Work and Social Administration, The University of Hong Kong, Hong Kong; \\ jennymyhuen@hku.hk \\ 3 Department of Epidemiology, School of Public Health, Shandong University \& Shandong University Centre \\ for Suicide Prevention Research, 44 Wenhuaxi Roas, Jinan 250012, China; ylu0403@163.com \\ 4 Department of Criminal Justice, Wayne State University, Detroit, MI 48202, USA; aa1051@wayne.edu \\ 5 The Mind Faculty, Kuala Lumpur 50480, Malaysia; tmaniam@yahoo.com \\ 6 The Hong Kong Jockey Club Centre for Suicide Research and Prevention, The University of Hong Kong, \\ Hong Kong; sfpyip@hku.hk \\ 7 Shandong University Center for Suicide Prevention Research, Shandong University, Jinan 250012, China \\ 8 Department of Sociology, State University of New York Buffalo State, Buffalo, New York, NY 14222, USA; \\ zhangj@buffalostate.edu \\ * Correspondence: jiacunxian@sdu.edu.cn \\ + Co-first authors.
}

Received: 15 November 2017; Accepted: 3 January 2018; Published: 7 January 2018

\begin{abstract}
The relationship between religious orientation and suicidality can be more complex in samples of low religious rate. The present study was conducted in China, one of the least religious countries, with the purpose of exploring different aspects of religious orientation and their relationships to suicidality. Among a university sample of 2074 respondents, 122 respondents reported being religious and responded to our measures of religious orientation and suicidality. Extrinsic religious orientation, while being distinct from intrinsic religious orientation, could be subdivided into personally-oriented and socially-oriented dimensions to predict suicidality in our sample. Results from regression analysis showed that respondents with higher intrinsic religious orientation and lower personally-oriented extrinsic religious orientation are more likely to have lower suicidality. These findings support that intrinsic orientation is embodied with positive outcomes whereas extrinsic orientation is embodied with negative outcomes. It is noteworthy that socially-oriented extrinsic religious orientation did not predict suicidality in our sample, as it was speculated that the role of socially-oriented extrinsic religious orientation cannot function when there are few religious people to socialize with in the community.
\end{abstract}

Keywords: religious orientation; suicidality; suicide prevention

\section{Introduction}

The relationship between religion and suicide was well noted by a French sociologist, Durkheim (Durkheim 1951), in his work about the phenomenon and social causes of suicide. Based on the data from some Western European countries, Durkheim concluded that Catholics and Jews had lower suicide rates than Protestants. Moreover, he proposed that the influence of religion on the rate of suicide is stronger when compared to the individual's education level. In particular, he noted that 
Jews, with generally high levels of education, should confer increased risks for suicide; however, they still presented with lower rates of suicide. At the time of the 1897 study, with the absence of well-established measures of religiosity, Durkheim simply made use of religious affiliation, a demographic variable, as the measurement of the religious or religiosity construct. After psychology evolved into a discipline of its own in the 1950s, psychological assessment using reliable and valid instruments was made known to the research field. In particular, in the later part of the 20th century and early 21st century, research in the psychology of religion made use of various self-report instruments to assess the construct of religiosity, including religious beliefs and practices, religious attitudes, religious orientation, religious development, religious commitment and involvement, religious experience, religious values, religiousness, religious coping, religious fundamentalism, religious attribution, etc. (Hill and Hood 1999).

Over 1200 empirical studies were conducted between 1872 and 2000 to examine the relationship between religion and health, and the number of studies has more than doubled from 2000 to 2009 (see Koenig et al. 2012 for a review). Findings from a majority of these studies suggest that religion or religiosity could serve as a protective factor against negative outcomes in life (e.g., suicide-related behavior). While investigations regarding the impact of religiosity have been conducted frequently in Western countries, there is a dearth of studies examining the role of religion in Asian countries, especially China. China is one of the most populous countries, and at the same time one of the least religious countries in the world. In a recent survey of 65 countries worldwide, the religious rate was found to be lowest in China, with about $90 \%$ respondents in China claiming to be not religious or atheist (WIN/Gallup International 2015). It is therefore important to attempt to replicate findings from Western countries regarding the moderate link between religiosity and suicidality in a country with a low religious rate, namely China. The present study was conducted in China for this purpose, and the significance of this study lies in being the first of its kind in China, using data from samples recruited from a relatively large province in China.

The present study focused on religious orientation, among other measures of religiosity. Religious orientation has been regarded as a construct that is the most empirically researched in the psychology of religion, whereas the Religious Orientation Scale (ROS) by Allport and Ross (1967) has been most frequently used for empirical research (Burris 1999). In this regard, the present study built on this dominant research paradigm in the psychology of religion. Some studies have provided evidence that religiosity (including religious orientation) is protective against suicidality (Cook 2014). Although religiosity has been hypothesized to be protective against suicidality, in some circumstances this effect did not replicate in other independent samples (e.g., Bagley and Ramsay 1989; Lester and Francis 1993; Lester and Walker 2017; Malihe and Motahare 2016; Taylor et al. 2011; Wingate et al. 2005). These inconsistent findings, as well as findings which appeared to be controversial and diverging to dominant hypotheses holding that religiosity is protective against suicidality, may be accounted for by the different aspects between different constructs of religiosity and within each construct of religiosity (e.g., intrinsic religious orientation and extrinsic religious orientation are two different aspects of religious orientation according to Allport and Ross) which function differentially as positive or negative factors. Indeed, a few researchers (e.g., Greening and Stoppelbein 2002; Walker and Bishop 2005) have found that intrinsic religious orientation, but not extrinsic religious orientation, was protective against suicidality.

The Religious Orientation Scale (ROS) was developed by Allport and Ross (1967) to measure two different aspects of religious orientation: intrinsic religious orientation and extrinsic religious orientation. Allport and Ross operationalized in a conceptual framework that intrinsic religious orientation is the internalization of religion as the master motive of one's life, whereas for extrinsic religious orientation, the religious involvement is used as a means to fit one's needs (e.g., for security, solace, sociability, and status). Consequently, it is assumed in Allport and Ross's conceptual framework that intrinsic religious orientation is embodied with positive outcomes, whereas extrinsic religious orientation is embodied with negative outcomes of religion. There are modifications of the original ROS 
across time and studies. In particular, Kirkpatrick (1989) conducted a psychometric analysis of the ROS based on a number of existing studies using the scale, and concluded that extrinsic religious orientation could be subdivided into personally-oriented extrinsic religious orientation and socially-oriented extrinsic religious orientation, to identify extrinsic religious orientation concerned with personal benefits and social benefits, respectively. In response to Kirkpatrick's distinction of personally-oriented extrinsic religious orientation and socially-oriented extrinsic religious orientation, Gorsuch and McPherson (1989) further revised the 21-item ROS to the 14-item Intrinsic/Extrinsic-Revised Scale (I/E-R), capturing eight intrinsic religious orientation, three personally-oriented extrinsic religious orientation, and three socially-oriented extrinsic religious orientation items. No study to date has directly examined the differential relationship, if any, between personally-oriented extrinsic religious orientation and socially-oriented extrinsic religious orientation to suicidality, though these two extrinsic constructs were found to relate differentially to other psychosocial and religious variables (e.g., Kirkpatrick 1989; McFarland 1989; Trimble 1997). Another purpose of this study was to further explore the association between different aspects of religious orientation and suicidality in a sample with a low religious rate. The relationship between religious orientation and suicidality can be more complex in samples of low religious rates. For example, it can be speculated that individuals high in socially-oriented extrinsic religious orientation cannot function adaptively when there are few religious people with which to socialize in the community.

In brief, the main aim of this study is to explore the nature of religious orientation in relation to suicidality in a less studied country with a low religious orientation rate. In addition, we wanted to examine the possibility that the different aspects of religious orientation (intrinsic, personally-oriented extrinsic, and socially-oriented extrinsic) are differentially associated with suicidality. The findings will suggest how different aspects of religious orientation are relevant to understanding or predicting the propensity to suicide and thus protecting religious individuals against suicide.

\section{Materials and Methods}

The survey was conducted in Jinan, the capital city of Shandong province, which is located south of Beijing, China. Shandong province has about 100 million residents, with about 7 million people living in its capital city, and it is the second largest province in terms of population and the third largest province in terms of economic size.

Two large public medical-related universities, Shandong University and Shandong University of Traditional Chinese Medicine, located in Jinan, were selected for the study. A stratified-clusteredrandom sampling method was used to sample students from three or four classes in each grade. The study was approved by the Institutional Review Boards and by the Ethics Committee of the Shandong University School of Public Health. Each participant verbally consented to participate in this study before completing the questionnaires during the class breaks.

The questionnaire packet was administered anonymously to the participants and they were asked to self-report to a battery of eight measures. Completing the full questionnaire packet took each respondent approximately $15 \mathrm{~min}$. Two measures in the packet were relevant to the present study:

1. Religious Orientation-Revised Scale (also known as Intrinsic/Extrinsic-Revised Scale) of Gorsuch and McPherson (1989): This scale was modeled on the Religious Orientation Scale developed by Allport and Ross (1967). Gorsuch and Venable (1983) first revised Allport and Ross's scale to an age-universal scale (i.e., usable for children, young adolescents, and adults), and Gorsuch and McPherson further revised the scale to include intrinsic religious orientation, personally-oriented extrinsic religious orientation, and socially-oriented extrinsic religious orientation dimensions. Of the 14 items, the Religious Orientation-Revised Scale has eight items measuring intrinsic religious orientation (e.g., "I enjoy reading about my religion."), six items measuring personally-oriented extrinsic religious orientation (e.g., "I pray mainly to gain relief and protection."), and six items measuring socially-oriented extrinsic religious orientation (e.g., "I go to church mostly to spend time with my friends."). A five-point response 
format as in the original work by Allport and Ross was used, ranging from 1 (strongly disagree) to 5 (strongly agree), with higher scores indicating higher levels of religious orientation. Given that intrinsic and extrinsic religious orientation are distinct constructs within the conceptual framework of Allport and Ross, separate scores were obtained for the Intrinsic scale (measuring intrinsic religious orientation) and the Extrinsic scale (measuring extrinsic religious orientation). The scales were further subdivided into separate scores for the Extrinsic personal scale (measuring personally-oriented extrinsic religious orientation) and the Extrinsic social scale (measuring socially-oriented extrinsic religious orientation). While there was no evidence of construct validity provided by Gorsuch and McPherson, the psychometric analysis by Kirkpatrick (1989) was taken as evidence in support of the three distinct dimensions of religious orientation: intrinsic religious orientation, personally-oriented extrinsic religious orientation, and socially-oriented extrinsic religious orientation. As reported by Gorsuch and McPherson, the reliability estimates of the Religious Orientation-Revised Scale for the Intrinsic scale, Extrinsic scale, Extrinsic personal scale, and Extrinsic social scale were $0.83,0.65,0.57$, and 0.58 , respectively.

2. Suicidal Behavior Questionnaire-Revised (SBQ-R; Osman et al. 2001): This scale was used in the present study as a measure of suicidality, encompassing suicide-related thoughts and behaviors. The scale is unidimensional and made up of four items, assessing suicide ideation and attempt in lifetime (Item 1), frequency of suicidal ideation over the past 12 months (Item 2), threat of suicide attempt (Item 3), and future likelihood of suicidal behavior (Item 4). One sample item is "How likely is it that you will attempt suicide in the future?" A total score for this measure, ranging from 3 to 18, is obtained by summing the scores of all the four items, with higher scores indicating higher levels of suicidality. The cut-off score between suicidal and non-suicidal for the undergraduate sample was 7 (i.e., a score of 7 or above will be classified as suicidal). As reported by Osman et al., the reliability estimate of the SBQ-R for the undergraduate sample was good (coefficient alpha $=0.76$ ).

Of the 2197 questionnaires handed out, 2074 students responded, at a high response rate of $94.4 \%$. The sample included 706 males (mean age $=19.86, \mathrm{SD}=1.50$ years) and 1368 females (mean age $=19.75$, $\mathrm{SD}=1.33$ years). The mean age of all respondents was 19.79 ( $\mathrm{SD}=1.39$ years). The sample consisted of 574 (27.7\%) freshmen (i.e., Year 1 students), 521 (25.1\%) sophomores (i.e., Year 2 students), 619 (29.8\%) juniors (i.e., Year 3 students), and 360 (17.4\%) seniors (i.e., Year 4 students). In terms of ethnicity, the majority of them were Han Chinese $(93.5 \%)$ and the remaining of them were Hui Chinese $(1.2 \%)$ and other minority ethnicities (5.3\%).

Additionally, of the 2074 respondents, only 122 of them (50 males and 72 females) reported being religious; this subgroup responded to the above measures, at a religious rate of about $6 \%$. Among them, $58(48 \%)$ were affiliated with Chinese folk religions, including Buddhism (32.8\%), Taoism (11.5\%), and Confucianism (3.3\%); 32 (26\%) were affiliated with Islam; 16 (13\%) were affiliated with Christianity, and $16(13 \%)$ were affiliated with other religions. In terms of ethnicity, slightly more than half of them $(58.2 \%)$ were Han Chinese, a few of them were Hui Chinese (11.5\%), and the remaining of them were from other minority ethnicities (30.3\%). Apart from gender and ethnicity, the distribution of other demographic characteristics of the study sample of 122 respondents was similar to that of the full sample of 2074 respondents presented above.

Prior to computing the scale scores and conducting the statistical analyses, preliminary analyses were conducted to examine if each of the scale items was functioning well, both conceptually and psychometrically, in each of the scales. An Intrinsic scale item ("I have often had a strong sense of God's presence.") was identified to be conceptually problematic, whereas all three reverse-coded Intrinsic scale items were identified to be psychometrically problematic and were excluded from the analyses. Having originated from the Christian-based religions in Western countries, many religiosity scale items made use of the term "God" in the question wording. Yet, the concept of "God" may not apply to some Chinese folk religions, especially Buddhism in which there is no God. This is made more complicated in our sample with which Buddhism is the most affiliated religion, and thus the Intrinsic scale item 
"I have often had a strong sense of God's presence." was discarded. As regards the reverse-coded items (also known as negatively worded items), researchers have suggested that these items may be a potential source of method bias (e.g., Podsakoff et al. 2003), and the responses to these items could be contaminated by respondent's inattention and confusion (e.g., Van Sonderen et al. 2013). Given the low item-total correlations of the negatively worded items (all correlation coefficients smaller than 0.4 ) and the presence of negative inter-item correlations between negatively worded items and positively worded items, these three negatively worded Intrinsic scale items were discarded. In a recent study by Aydemir and Eğilmez (2010), these three items were similarly excluded from the analysis.

The psychometric properties of the scales were examined to provide validity evidence on its internal structure. For both scales, the internal consistency was assessed using Cronbach's alpha. Exploratory factor analysis was used to explore how the scale items of the Religious Orientation-Revised Scale reflected the underlying factor structures that were intended to measure. Multiple linear regression was used to test the regression model examining the association between the three aspects of religious orientation (as measured by the Intrinsic scale, Extrinsic personal scale, and Extrinsic social scale of the Religious Orientation-Revised Scale) and suicidality (as measured by the Suicidal Behavior Questionnaire-Revised). All analyses were conducted using SPSS Statistics Version 23.0 (IBM Corp. 2015).

\section{Results}

The descriptive statistics for each of the scale scores are shown in Table 1, along with Cronbach's alpha as reliability estimate for each scale. The mean score on the SBQ-R was 1.28 (SD = 0.64), which was far below the cut-off score of 7 for the undergraduate sample, suggesting that the respondents were low in suicidality. From the Cronbach's alphas (one around 0.7 and others above 0.7 ), the internal consistency for all the scales were satisfactory.

Table 1. Descriptive Statistics and Cronbach's Alphas for the Scales.

\begin{tabular}{ccc}
\hline Scale & Mean (SD) & Cronbach's Alpha $^{\mathbf{1}}$ \\
\hline Intrinsic scale (I) & $3.10(0.88)$ & 0.76 \\
Extrinsic scale (E) & $2.72(0.81)$ & 0.80 \\
Extrinsic personal scale (Ep) & $3.05(0.94)$ & 0.73 \\
Extrinsic social scale (Es) & $2.39(1.02)$ & 0.88 \\
Suicidal Behavior Questionnaire-Revised (SBQ-R) & $1.28(0.64)$ & 0.66 \\
\hline
\end{tabular}

${ }^{1}$ Cronbach's Alpha based on standardized items.

Exploratory factor analysis was conducted on the 10 items measuring religious orientation to examine the underlying factor structure of the religious orientation construct. Table 2 shows the eigenvalues for the 10 items related to the dimensions of the religious orientation construct and their percentages of total variance explained. Based on the criterion of extracting all the factors with an eigenvalue greater than 1 (Kaiser 1974), the number of factors to be extracted was 3 (known as a three-factor solution). The three factors accounted for about $72 \%$ of the variability, which is a substantial amount of variance. A Principal Axis Factoring extraction method was used with Equamax rotation (same extraction and rotation methods as in the validation study on the same scale employed by Genia 1993). Table 3 shows the factor loadings after the Equamax rotation. The factor loadings were evaluated using Kline's criteria (Kline 1994) of 0.30 or higher as acceptable. One Intrinsic scale item (Item 4) and all three Extrinsic social scale items (Items 1, 2, and 3) had acceptable loadings of 0.30 or higher on Factor 1. Next, three of the Intrinsic scale items (Items 2, 3, and 4) and all three of the Extrinsic Personal scale items (Items 1, 2, and 3) had acceptable loadings on Factor 2. All four of the Intrinsic scale items (Items 1, 2, 3, and 4) had acceptable loadings on Factor 3. Taken together, three of the 10 items are considered complex items because of moderate loadings on two (Intrinsic scale Items 2 and 3) or three factors (Intrinsic scale item 4). Nonetheless, the findings provide preliminary 
evidence in support of the three-factor solution. In other words, there were three factors (namely socially-oriented extrinsic religious orientation, personally-oriented extrinsic religious orientation, and intrinsic religious orientation) underlying religious orientation in the current sample data.

Table 2. Religious orientation: eigenvalues and their percentages of variance accounted for.

\begin{tabular}{cccc}
\hline Factor(s) & Eigenvalue & \% of Variance Accounted for & Cumulative $\%$ of Variance Accounted for \\
\hline 1 & 4.04 & $40.38 \%$ & $40.38 \%$ \\
2 & 2.03 & $20.31 \%$ & $60.69 \%$ \\
3 & 1.10 & $11.00 \%$ & $71.69 \%$ \\
4 & 0.75 & $7.53 \%$ & $79.22 \%$ \\
5 & 0.56 & $5.57 \%$ & $84.79 \%$ \\
6 & 0.40 & $3.98 \%$ & $88.77 \%$ \\
7 & 0.37 & $3.74 \%$ & $92.51 \%$ \\
8 & 0.34 & $3.35 \%$ & $95.86 \%$ \\
9 & 0.25 & $2.50 \%$ & $98.36 \%$ \\
10 & 0.16 & $1.64 \%$ & $100 \%$ \\
\hline
\end{tabular}

Table 3. Religious orientation: factor loadings ${ }^{1}$ of principal axis factoring with Equamax rotation.

\begin{tabular}{cccc}
\hline Scale-Item & Factor 1 & Factor 2 & Factor 3 \\
\hline Intrinsic scale-Item 1 & 0.04 & 0.05 & $\mathbf{0 . 9 4}$ \\
Intrinsic scale-Item 2 & 0.04 & $\mathbf{0 . 4 1}$ & $\mathbf{0 . 6 2}$ \\
Intrinsic scale-Item 3 & 0.00 & $\mathbf{0 . 6 9}$ & $\mathbf{0 . 4 0}$ \\
Intrinsic scale-Item 4 & $\mathbf{0 . 4 4}$ & $\mathbf{0 . 3 0}$ & $\mathbf{0 . 3 5}$ \\
Extrinsic personal scale-Item 1 & 0.27 & $\mathbf{0 . 7 5}$ & 0.07 \\
Extrinsic personal scale-Item 2 & 0.09 & $\mathbf{0 . 6 8}$ & 0.28 \\
Extrinsic personal scale-Item 3 & 0.29 & $\mathbf{0 . 5 2}$ & 0.11 \\
Extrinsic social scale-Item 1 & $\mathbf{0 . 8 5}$ & 0.15 & 0.07 \\
Extrinsic social scale-Item 2 & $\mathbf{0 . 9 1}$ & 0.09 & 0.08 \\
Extrinsic social scale-Item 3 & $\mathbf{0 . 7 3}$ & 0.17 & -0.03 \\
\hline \multicolumn{2}{c}{ 1 Factor loadings equal to or larger than 0.30 are in bold. }
\end{tabular}

Multiple linear regression was carried out to test the regression model examining the association between the three aspects of religious orientation (as measured by the Intrinsic scale, Extrinsic personal scale, and Extrinsic social scale) and suicidality. Suicidality score was log-transformed prior to being entered into the regression model. This was because suicidality scores are usually highly skewed, as expected in nearly all non-clinical samples in which the suicide propensity are low. The model with three predictors was statistically significant, $F(3,121)=2.71, p<0.05$, and it accounted for about $7 \%$ of the variance in suicidality $\left(R^{2}=0.07\right)$. Table 4 shows the regression coefficients of different aspects of religious orientation as predictors of suicidality. Intrinsic religious orientation, $\beta=-0.21$, $p<0.05$, and personally-oriented extrinsic religious orientation, $\beta=0.31, p<0.01$, were significantly related to suicidality. From the direction of the regression coefficients, individuals with lower intrinsic religious orientation and higher personally-oriented extrinsic religious orientation are more likely to have higher suicidality, and vice versa. Socially-oriented extrinsic religious orientation was not significantly associated with suicidality, $\beta=-0.03, p=0.76$.

Table 4. Religious orientation: regression coefficients predicting suicidality.

\begin{tabular}{cccc}
\hline & \multicolumn{2}{c}{ Unstandardized Coefficients } & Standardized Coefficients \\
\hline & $\boldsymbol{B}$ & $\boldsymbol{S E}$ & $\boldsymbol{\beta}$ \\
\hline Intrinsic religious orientation & -0.012 & 0.006 & $-0.212^{*}$ \\
Personally-oriented extrinsic religious orientation & 0.021 & 0.008 & $0.312^{* *}$ \\
Socially-oriented extrinsic religious orientation & -0.002 & 0.006 & -0.030 \\
\hline
\end{tabular}

${ }^{*} p<0.05 ; * * p<0.01$




\section{Discussion}

The findings of the present study provide preliminary evidence of a three-factor model of religious orientation and reveal that the three different aspects of religious orientation are differentially associated with suicidality. Exploratory factor analysis showed a reasonable fit of the scale items to the three-factor structure for the measure of religious orientation, which can be regarded as socially-oriented extrinsic religious orientation, personally-oriented extrinsic religious orientation, and intrinsic religious orientation. In this Asian sample with a low religious rate (about $6 \%$ ), responses from individuals with higher intrinsic religious orientation were related to decreased propensity for suicide, whereas the responses of individuals with higher personally-oriented extrinsic religious orientation were related to increased propensity for suicide. While intrinsic religious orientation could be considered as a protective factor against suicidality, and personally-oriented extrinsic religious orientation as risk factor for suicide, there was little evidence that socially-oriented extrinsic religious orientation was a protective factor or a risk factor of suicidality in our sample.

Interpreted in light of previous studies, the results obtained in the present study in China (one of the least religious countries) were both consistent with and diverging from previous studies conducted in Western countries with moderate or high religious rates. It should be noted that though we made use of the Religious Orientation-Revised Scale modeled on Allport and Ross's work (Allport and Ross 1967) in the present study, the scale was not designed to address the relation between different aspects of religious orientation and suicidality, and in fact no previous studies have directly addressed this issue. The original work by Allport and Ross aimed to examine intrinsic and extrinsic religious orientation in the context of personality and prejudice; for instance, they found that people with high intrinsic orientation are less prejudicial. The relationship between religious orientation and suicidality found in the present study were generally in line with the key assumption by Allport and Ross in their conceptual framework of intrinsic and extrinsic religious orientation that intrinsic orientation is embodied with positive outcomes, whereas extrinsic orientation is embodied with negative outcomes of religions. Yet, results from the present study showed that extrinsic religious orientation conferred increased risk for suicide only when the extrinsic religious orientation was personally-oriented but not socially-oriented in nature. Our sample characterized by a low religious rate allowed us to capture the difference between personally-oriented and socially-oriented extrinsic religious orientation. Due to the low religious rate, people adhering to a religion (i.e., religionists) cannot generate an adequate or effective social network or social support among co-religionists for the construct of socially-oriented extrinsic religious orientation to become relevant, while the construct of personally-oriented extrinsic religious orientation is still relevant regardless of other co-religionists. Given this distinctiveness observed between personally-oriented and socially-oriented extrinsic religious orientation, extrinsic religious orientation is better conceptualized as two distinct factors, rather than the original one factor formulation in Allport and Ross's work. The three-factor solution validated in this study is consistent with that of other previous studies validating the three distinct dimensions of religious orientation (e.g., Brewczynski and MacDonald 2006; Genia 1993; Kirkpatrick 1989). While supporting the overall adequacy of the three-factor structure of religious orientation, the cross-loadings of scale items observed in our study suggested that the factor structure of religious orientation may still be more complex than what we have understood, and that the measuring items may not interpreted in a conceptually similar manner by respondents across cultures. For instance, we have concerns over the use of the term "God", which may be interpreted differently by Chinese folk religionists and Christian-based religionists. When the item having the term "God" (an intrinsic religious orientation item) was included in the analysis, the predictive power of intrinsic religious orientation as a whole to suicidality decreases, $\beta=-0.19, p=0.10$, holding other predictors in the regression model constant. Adaptation may be made to the measuring item as appropriate, such as rephrasing the term "God" in a way that measures whether the respondent believes there is something or someone who is beyond the physical world and what physics can prove today instead of whether the respondent believes in "God". In addition, new items which are not reverse-coded may be added to the Intrinsic scale to 
replace those reverse-coded (negatively worded) items as appropriate to avoid certain items becoming a method of bias influencing responses.

The interesting finding that socially-oriented extrinsic religious orientation did not relate significantly to suicidality in our sample with a low religious rate can also be interpreted from the perspective of the four working hypotheses by Stack and Kposowa (2016) on the social theory of religions in terms of suicidality: (1) Social Integration; (2) Religious Commitment; (3) Social Networking (Social Support); and (4) Moral Community, in understanding religion and suicide. Stack and Kposowa reviewed theories surfacing since the 1950s and 1960s about the relationship between suicide and religion, and categorized them based on the above four hypotheses on how religion manifests as a protective factor against suicidality. Having a socially-oriented religious orientation in a country where the religious rate is low renders individuals unable to benefit in terms of the Social Networking (Social Support) hypothesis compared to those in a country where the religious rate is high. In accordance with the Moral Community hypothesis, it is postulated that religionists can form a moral community with protective effects within the community, and yet the moral community environment that can be formed in a country with a low religious rate is weak. With little social networking or social support, and in a weak moral community environment, the effect of socially-oriented religious orientation on suicidality cannot take place and thus the protective effect is absent in our sample with a low religious rate.

In a broader context, the findings that intrinsic religious orientation can be a protective factor against suicidality has implications for suicide prevention and the treatment of psychiatric patients. Indeed, there have been position statements, such as position statements issued by the Royal College of Psychiatrists (2013) and World Psychiatric Association (2015), to affirm the importance of considering religion in clinical practice and provide relevant recommendations for good practice of how to address religion in clinical practice. For instance, psychiatrists and psychologists could include religion in their diagnostic form, and if the patients or clients report being religious, the practitioners could be open to discuss it, or refer patients to the relevant clergymen for religious counselling. There have also been suggestions that if practitioners know more about the role religion plays, they can keep the clergymen informed and work together in a formal system of collaboration (e.g., VanderWeele et al. 2017). Based on our findings that intrinsic religious orientation is protective against suicidality, practitioners and clergymen could work together to facilitate patients to find their master motive in religion and live according to the religion (i.e., addressing patient's intrinsic religious orientation). This should be feasible for more developed countries, where there are clergymen working in hospitals with practitioners.

A major limitation of the present study should be noted, which is the small sample size coupled with the use of a student sample. The analyses were conducted based on a sample of 122 students from two medical-related university campuses in the capital city of one province. The generalizability of results from this small sample to other provinces or the whole of China is highly questionable. Also, the observations from the current sample in the age-group of university students cannot represent those of other age groups. Moreover, the small sample size of respondents identifying as religious results in an even smaller sample size of the sub-groups of respondents with different religion affiliations, making sub-group comparisons by religion affiliation unfeasible. The limitations that have been highlighted provide directions for future research. Firstly, studies similar to the present study can be conducted in other provinces (including rural areas) in China, given that religious rates and socioeconomic/urbanization levels could differ substantively across provinces. Effort can also be extended to cover some other less studied countries in East Asia, Southeast Asia, and other understudied parts of the world such as South America and Africa. In the beginning of the 21st century, there were reports of gradually declining or flattening religious rates in certain Western countries, and reports of fast-growing religious rates in China. This study can be replicated when the religious rate of China reaches a certain milestone, or a longitudinal design can be used. Secondly, similar studies can be conducted for other age groups and clinical samples. There have been similar studies yielding 
different results in clinical samples, such as psychiatric patients. For example, Khan and Ali (2016) found that among psychiatric patients, extrinsic religious orientation was more protective against suicidality than intrinsic religious orientation.

The spiritual aspect of suicide prevention, which can be approached by the religiosity and spirituality of individuals, has not yet been fully understood and explored. In view of this, the present study explored whether religious orientation is relevant to understanding or predicting the propensity to suicide and thus to protecting religious individuals against suicide. Future studies could further explore how different aspects of religiosity and spirituality can protect individuals against suicide, as well as identify risk factors leading to suicide (such as hopelessness and depression). Like this study, studies devoted to suicide prevention, religion, and spirituality should move beyond philosophical theology to psychological measurement and testing based on empirical data, for a promising avenue to understanding and interpreting religiosity or spirituality and its relationship to suicidality in different samples and communities.

Acknowledgments: The authors are indebted to Professor Augustine Osman and Professor David Lester for reading this manuscript with valuable feedback. Also, the authors are thankful to the students at Shandong University and Shandong University of Traditional Chinese Medicine who participated in the survey.

Author Contributions: B.L. and C.X.J. designed the survey; L.Y. coordinated the data collection as the team leader in administrating the survey; J.H., B.L. and P.Y. conceived the focus of the study; S.S. assisted with the conceptualization of the study; J.H. analysed the data; B.L. and J.H. wrote the manuscript; C.X.J. and J.H. revised the manuscript; C.X.J., J.Z. and T.M. provided advices in the form of academic consultation; all authors read the manuscript; C.X.J. as the corresponding author made the final decision to submit this paper.

Conflicts of Interest: The authors declare no conflict of interest.

\section{References}

Allport, Gordon W., and J. Michael Ross. 1967. Personal Religious Orientation and Prejudice. Journal of Personality and Social Psychology 5: 432-43. [CrossRef] [PubMed]

Aydemir, Muzaffer, and Özüm Eğilmez. 2010. An Important Antecedent of Ethical/Unethical Behavior: Religiosity. Eurasian Journal of Business and Economics 3: 71-84.

Bagley, Chris, and Richard Ramsay. 1989. Attitudes towards Suicide, Religious Values and Suicidal Behavior. In Suicide and its Prevention: The Role of Attitude and Imitation. Edited by René Diekstra, Ronald Marris, Stephen Platt, Armin Schmidtke and Sonneck G. Leiden: Brill, pp. 78-90.

Brewczynski, Jacek, and Douglas A. MacDonald. 2006. Confirmatory Factor Analysis of the Allport and Ross Religious Orientation Scale with Polish Sample. The International Journal for the Psychology of Religion 16: 63-76. [CrossRef]

Burris, Christopher. 1999. Scales of Religious Orientation. In Measures of Religiosity. Edited by Peter Hill and Ralph Wood. Birmingham: Religious Education Press, pp. 119-21.

Cook, Christopher C. H. 2014. Suicide and Religion. The British Journal of Psychiatry 204: 254-55. [CrossRef] [PubMed]

Durkheim, Émile. 1951. Suicide: A Study in Sociology. New York: Free Press, First Published 1897.

Genia, Vicky. 1993. A Psychometric Evaluation of the Allport-Ross I/E Scales in a Religiously Heterogeneous Sample. Journal of the Scientific Study of Religion 32: 284-90. [CrossRef]

Gorsuch, Richard L., and Susan E. McPherson. 1989. Intrinsic/Extrinsic Measurement: I/E-Revised and Single-Item Scales. Journal for the Scientific Study of Religion 28: 348-54. [CrossRef]

Gorsuch, Richard L., and G. Daniel Venable. 1983. Development of an 'Age Universal' I-E Scale. Journal of the Scientific Study of Religion 22: 181-87. [CrossRef]

Greening, Leilani, and Laura Stoppelbein. 2002. Religiosity, Attributional Style, and Social Support as Psychosocial Buffers for African American and White Adolescents' Perceived Risk for Suicide. Suicide and Life-Threatening Behavior 32: 404-17. [CrossRef] [PubMed]

Hill, Peter C., and Ralph W. Hood. 1999. Measures of Religiosity. Birmingham: Religious Education Press.

IBM Corp. 2015. IBM SPSS Statistics for Windows, (version 23.0); Armonk, New York, USA: IBM Corp.

Kaiser, Henry F. 1974. An Index of Factorial Simplicity. Psychometrika 39: 31-36. [CrossRef] 
Khan, Farah, and Uzma Ali. 2016. Impact of Religious Orientation on Suicide Behaviors among Psychiatric Patients. Journal of Pakistan Psychiatric Society 13: 34-36.

Kirkpatrick, Lee A. 1989. A Psychometric Analysis of the Allport-Ross and Feagin Measures of Intrinsic-Extrinsic Religious Orientation. In Research in the Social Scientific Study of Religion. Edited by Monty Lynn and David Moberg. Greenwich: JAI Press.

Kline, Paul. 1994. An Easy Guide to Factor Analysis. London: Routledge.

Koenig, Harold G., Dana E. King, and Verna Benner Carson. 2012. Handbook of Religion and Health, 2nd ed. New York: Oxford University Press.

Lester, David, and Leslie J. Francis. 1993. Is Religiosity Related to Suicidal Ideation after Personality and Mood are Taken into Account? Personality and Individual Differences 15: 591-92. [CrossRef]

Lester, David, and Rheeda L. Walker. 2017. Religiosity is a Protective Factor for Suicidal Ideation in European American Students but Not in African American Students. OMEGA-Journal of Death and Dying 74: 295-303. [CrossRef] [PubMed]

Malihe, Beigzade, and Pilevarzadeh Motahare. 2016. Religious Orientation and Suicidal Thoughts among Students. International Journal of Humanities and Cultural Studies 3: 1554-65.

McFarland, Sam G. 1989. Religious Orientations and the Targets of Discrimination. Journal for the Scientific Study of Religion 28: 324-36. [CrossRef]

Osman, Augustine, Courtney L. Bagge, Peter M. Gutierrez, Lisa C. Konick, Beverly A. Kopper, and Francisco X. Barrios. 2001. The Suicidal Behaviors Questionnaire-Revised (SBQ-R): Validation with Clinical and Nonclinical Samples. Assessment 8: 443-54. [CrossRef] [PubMed]

Podsakoff, Philip M., Scott B. MacKenzie, and Jeong-Yeon Lee. 2003. Common Method Biases in Behavioral Research: A Critical Review of the Literature and Recommended Remedies. Journal of Applied Psychology 88: 879-903. [CrossRef] [PubMed]

Royal College of Psychiatrists. 2013. Recommendations for Psychiatrists on Spirituality and Religion. Available online: https:/ / www.rcpsych.ac.uk/pdf/PS03_2013.pdf (accessed on 15 August 2017).

Stack, Steven, and Augustine J. Kposowa. 2016. Sociological Perspectives on Suicide: A Review and Analysis of Marital and Religious Integration. In The International Handbook of Suicide Prevention. Edited by Rory O'Connor and Jane Pirkis. New York: John Wiley \& Sons.

Taylor, Robert J., Linda M. Chatters, and Sean Joe. 2011. Religious Involvement and Suicidal Behaviour among African Americans and Black Caribbeans. The Journal of Nervous and Mental Disease 199: 478-86. [CrossRef] [PubMed]

Trimble, Douglas E. 1997. The Religious Orientation Scale: Review and Meta-analysis of Social Desirability Effects. Educational and Psychological Measurement 57: 970-86. [CrossRef]

Van Sonderen, Eric, Robbert Sanderman, and James C. Coyne. 2013. Ineffectiveness of Reverse Wording of Questionnaire Items: Let's Learn from Cows in the Rain. PLoS ONE 8: e68967. [CrossRef] [PubMed]

VanderWeele, Tyler J., Tracy A. Balboni, and Howard K. Koh. 2017. Health and Spirituality. JAMA 318: 519-20. [CrossRef] [PubMed]

Walker, Rheeda L., and Shaughna Bishop. 2005. Examining a Model of the Relation between Religiosity and Suicidal Ideation in a Sample of African American and While College Students. Suicide and Life-Threatening Behavior 35: 630-39. [CrossRef] [PubMed]

WIN/Gallup International. 2015. Losing our Religion? Two Thirds of People Still Claim to be Religious. Sofia: WIN/Gallup International.

Wingate, Laricka R., Leonardo Bobadilla, Andrea B. Burns, Kelly C. Cukrowicz, Annya Hernandez, Rita L. Ketterman, Jennifer Minnix, Scharles Petty, Anthony J. Richey, Natalie Sachs-Ericsson, and et al. 2005. Suicidality in African American Men. Suicide and Life-Threatening Behavior 35: 615-29. [CrossRef] [PubMed]

World Psychiatric Association. 2015. WPA Position Statement on Spirituality and Religion in Psychiatry. Available online: http://www.wpanet.org/uploads/Position_Statement/WPA\% 20position\%20Spirituality\%20statement\%20final\%20version_rev2\%20on\%20Spirituality.pdf (accessed on 15 August 2017).

(C) 2018 by the authors. Licensee MDPI, Basel, Switzerland. This article is an open access article distributed under the terms and conditions of the Creative Commons Attribution (CC BY) license (http:/ / creativecommons.org/licenses/by/4.0/). 